F. Reprod. Fert. (1971) 27, 167-176

\title{
THE INFLUENCE OF MALE PROXIMITY AND DIETARY RESTRICTION ON THE OESTROUS CYCLE OF THE RAT
}

\author{
K. PURVIS, K. J. GOOPER AND N. B. HAYNES \\ University of Nottingham School of Agriculture, \\ Sutton Bonington, Loughborough, Leicestershire
}

(Received 15th October 1970)

\begin{abstract}
Summary. Continuous pairing of underfed female rats, each with the same male rat under conditions which prevented bodily contact, significantly lowered the frequency of oestrus and increased the number of females which ceased to show cyclic activity when compared to underfed females not exposed to males or to those exposed to different males each day for $15 \mathrm{hr}(P<0.01)$.
\end{abstract}

\section{INTRODUCTION}

It is known that association with the male can have a marked stimulatory influence on the reproductive behaviour of the female in a number of species. A shortening of oestrous cycles and synchronization of oestrus in grouped mice, for example, is brought about by the presence of a male (Whitten, 1958). Allied phenomena have been reported for the sheep (Schinckel, 1954; Radford $\&$ Watson, 1957), pig (Signoret \& du Mesnil du Buisson, 1961), goat (Shelton, 1960) and rat (Hughes, 1964). Cooper \& Haynes (1967) demonstrated that the introduction of different males each day for $15 \mathrm{hr}$ into the cages of female rats showing lengthened cycles due to dietary restriction resulted in a significant shortening of the oestrous cycle. A number of rats did not mate at the first oestrus and the subsequent cycle was again of shorter duration than those before introduction of the male. This indicated that the female continued to respond to the male. It was recently shown that physical contact with the male was not necessary for this response, shorter oestrous cycles being observed when males were placed near underfed females for $15 \mathrm{hr} /$ day with contact prevented by a wire mesh barrier (McNeilly, Cooper \& Crighton, 1970). In both these experiments, response to the male was determined after subjecting the female to a period of underfeeding. This communication describes experiments carried out to investigate whether the stimulatory effect of the male on cyclic activity is a long-term one and is sufficient to suppress the effect of underfeeding when both are applied simultaneously for several oestrous cycles.

\section{MATERIALS AND METHODS}

Virgin rats from the Sutton Bonington colony of Wistar origin were used; the 
males were 16 weeks old and the females 18 weeks old at the start of the experiments. The accommodation consisted of metal cages in batteries of forty in a room maintained under $12 \mathrm{hr}$ light $/ 12 \mathrm{hr}$ dark, and at a temperature of $21 \pm 2^{\circ}$ C. Each cage was divided into two equal compartments by a double wire mesh barrier $2 \mathrm{~cm}$ wide which prevented physical contact between the rats in either half. One female rat was placed in each battery cage and occupied half of it. The other half was reserved for males when required. Where possible, interaction between groups of animals was reduced by placing individuals on one treatment as far away as possible from individuals exposed to a different set of conditions. All animals had free access to water and were fed a standard ration described by Cooper, Haynes \& Lamming (1970). Animals on a restricted diet were fed between 16.00 and 17.00 hours. Oestrous cycles were monitored by vaginal smears carried out daily between 16.00 and 18.00 hours.

Statistical evaluations were by analysis of variance unless stated otherwise.

Experiment 1. The effect of continuous association with males on the oestrous cycles of underfed female rats

Previous work (Cooper \& Haynes, 1967) had been carried out using a discontinuous exposure period of male to female and it was considered that maximal stimulation would be obtained by increasing the degree of exposure. In consequence, in the first experiment, males were placed with females continuously.

The experiment was carried out during November and December. Sixty female rats were allowed to complete three oestrous cycles on an unrestricted feed intake with no males present. Nine had cycle abnormalities and were discarded. The remainder were randomly divided into three groups as follows: Group 1: Twenty-eight were fed $65 \%$ by weight of the average daily intake of females allowed unlimited access to food (Group 3), based on a 4-day feeding period and were maintained in the continuous presence of males. The males were introduced (one male to each female) at the same time as food restriction was imposed and remained until the experiment finished.

Group 2: Fifteen were fed as Group 1 and were not exposed to males.

Group 3: Eight were allowed unrestricted access to food in the continuous presence of males.

All males had free access to food and water. Treatments were started between 16.00 and 17.00 hours on the first day of a dioestrous period. With the exception of Group 1, the experiment was terminated when the majority of underfed animals had ceased cyclic activity. At this stage, the males were removed from Group 1 and daily vaginal smears were collected over a further three cycles.

The second experiment was carried out to confirm the depressive effect of continuous exposure to the same male found in Exp. 1. The situation was also compared with one known from previous work to give a stimulatory response, namely association with different males for $15 \mathrm{hr} /$ day.

Experiment 2. A comparison of the effect of continuous association with the same male and discontinuous association with different males on reproductive activity of the underfed female rat

The experiment was performed during February and March. Forty-four 
normally cycling female rats were randomly allocated to four groups as follows: Group 4: Ten were fed $65 \%$ by weight of the average daily intake of females allowed unrestricted access to food (Group 7), based on a 4-day feeding period and were maintained in the continuous presence of males.

Group 5: Ten were fed as Group 4 and exposed for $15 \mathrm{hr} /$ day between 06.00 and 21.00 hours to male rats selected daily at random from a communal cage. Group 6: Ten were fed as Group 4 with no males present.

Group 7: Fourteen were allowed unrestricted access to food in the continuous presence of males.

The underfed females still showing definitive cyclic activity were killed at the pro-oestrus of the fifth cycle. Both wet uterine weight (weight of fresh uterus plus fluid) and blotted uterine weight (weight of fresh uterus after removal of fluid by blotting with filter papers) were recorded. All ovaries were examined visually to confirm the pro-oestrous condition of the animal.

Experiment 3. Oestrous frequencies at different times of year for rats allowed unrestricted access to food

This formed part of an independent experiment and is included in view of the difference in results between the animals on unrestricted feeding in Exps 1 and 2.

Sixty virgin female rats, maintained as previously described and allowed unlimited access to food, were used. The rats were obtained in batches of twenty and were 16 weeks old at the start of each of the following treatments: Group 8: Daily vaginal smears were taken during part of July-August.

Group 9: Daily vaginal smears were taken during part of October-November. Group 10: Daily vaginal smears were taken during part of December-January. No male rats were present at any time.

\section{Experiment 1}

\section{RESULTS}

Mean cycle lengths for the three groups are shown in Text-fig. 1. Inanition significantly lengthened the first oestrous cycle of underfed females in isolation (Group 2) when compared with those in continuous association with males (Group 1) and those (Group 3) on unrestricted feeding $(P<0.001)$. Underfed animals in contact with males (Group 1) demonstrated a significant increase in the second cycle compared to the first $(P<0 \cdot 05)$. Unrestricted females (Group $3)$ maintained a constant cycle length until males were introduced. The immediate cycle after male introduction was significantly lengthened $(P<0.05)$ to a value characteristic of underfed animals. Subsequent cycle lengths were further increased until the male rats were removed when a significant shortening of the cycle resulted $(P<0.001)$.

The daily oestrous frequencies, defined as the number of rats showing an oestrous period in each 5 days divided by the number of rats per group, is shown in Text-fig. 2, together with regression analyses. Animals exposed continuously to males throughout the period of inanition were more sensitive to diet restriction as indicated by the significant difference in the slope of the 
Food restriction started

(1)

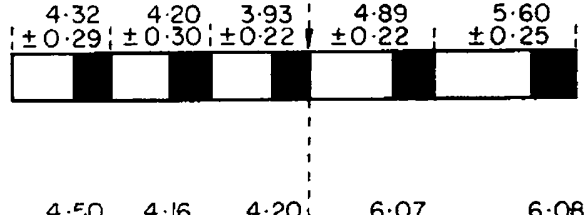

(2)

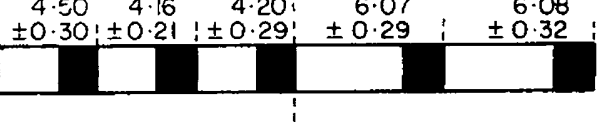

(3)

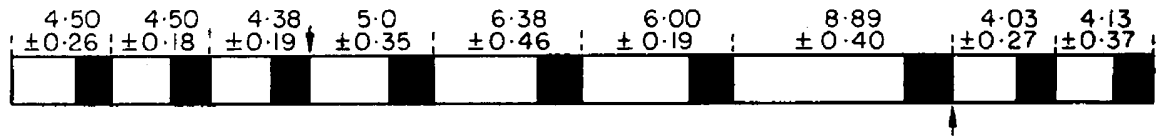

TEXT-FIG. 1. Average cycle lengths of rats in Exp. 1: (1) underfed females in continuous association with the same male; (2) underfed females in isolation; (3) females on an unrestricted feed intake. Males were introduced at $\downarrow$ and removed at $\uparrow$. Solid bars represent pro-oestrus, oestrus and metoestrus; unshaded bars dioestrus. Values between vertical broken lines, mean cycle lengths \pm S.E.

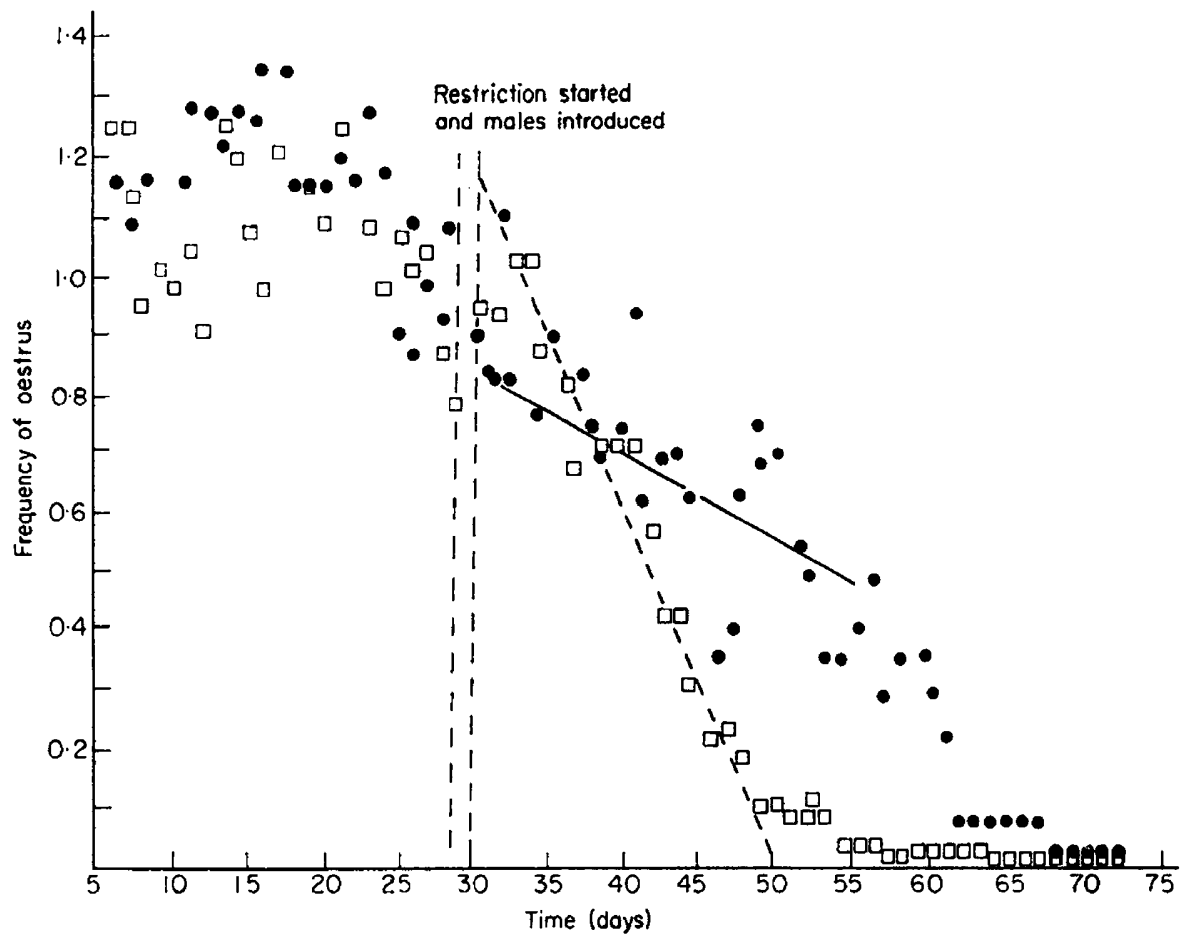

Text-pig. 2. Frequency of oestrus in two groups of rats from Exp. 1: (a) fed a restricted diet in the continuous presence of the same male, $\square$; regression line (Day 30 to $50 .--$ - - $_{\text {- }}$ ) $y=2 \cdot 30-0.05 x, r=-0.97$; (b) fed a restricted diet in the absence of a male, 0 ; regression line (Day 30 to $55 \longrightarrow$ ) $y=1.22-0.02 x, r=-0.57$. Frequency of oestrus is expressed as the number of oestrous smears shown by a group over a period of 5 days divided by the total number of rats in the group. 
regression lines $(P<0.001)$. The number of animals becoming anoestrous after the third cycle is shown in Table 1 . The number of anoestrous females was significantly higher $\left(P<0.01 ; \chi^{2}\right.$ test $)$ in the underfed group associated with males than in the underfed group with no males.

TABLE 1

GYGLIG AGTIVITY OF FEMALE RATS (EXPERIMENT 1)

\begin{tabular}{c|c|c|c}
\hline \multirow{2}{*}{\begin{tabular}{c|c} 
Nycle after which \\
rats became anoestrous
\end{tabular}} & \multicolumn{3}{|c}{ No. of rats becoming anoestrous } \\
\cline { 2 - 4 } & Unrestricted feed & \multicolumn{2}{|c}{ Underfed } \\
\cline { 2 - 4 } & Continuous male & No male & Continuous male \\
\hline First cycle & $0 / 8$ & $0 / 15$ & $2 / 28$ \\
Second cycle & $0 / 8$ & $3 / 15$ & $8 / 28$ \\
Third cycle & $0 / 8$ & $5 / 15$ & $22 / 28$ \\
\hline
\end{tabular}
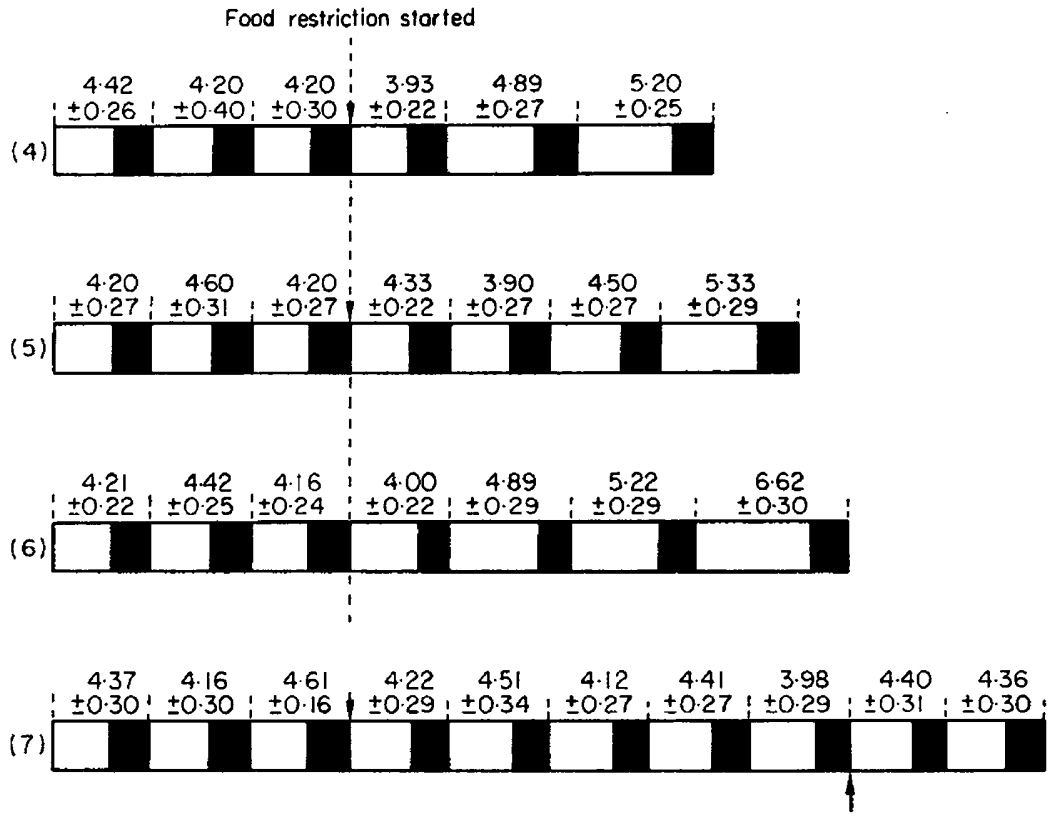

TEXT-FIG. 3. Average cycle lengths of rats in Exp. 2: (4) underfed females in continuous association with the same male; (5) underfed females periodically exposed to different males; (6) underfed females in isolation; (7) females on an unrestricted feed intake. Explanation as for Text-fig. 1.

\section{Experiment 2}

Mean cycle lengths for the four groups are shown in Text-fig. 3. Exposure of underfed female rats to males, either continuously with the same male (Group 4) or discontinuously with different males (Group 5), did not significantly modify the length of the first oestrous cycle from that of underfed or unrestricted 
controls (Groups 6 and 7). Both the underfed females in continuous association with the same male (Group 4) and underfed controls (Group 6) showed a significant increase in the length of the second oestrous cycle over the first $(P<0.01)$. Females exposed to different males for $15 \mathrm{hr} /$ day (Group 5 ) failed to show this increase and exhibited a slight shortening of the cycle. All groups showed a gradual lengthening of subsequent cycles, although the cycle lengths of females exposed periodically to different males (Group 5) were, in all cases, shorter than the equivalent cycles of other groups $(P<0.01$ and $<0.05$ for differences between the third and fourth cycles, respectively). In this experiment introduction of the male had no effect on the oestrous cycles of animals given unrestricted access to food (Group 7).

Continuous association significantly increased the number of females becoming anoestrous by the fourth cycle when compared to females exposed to males $15 \mathrm{hr} /$ day and underfed controls $\left(P<0.01 ; \chi^{2}\right.$ test) (Table 2).

TABLE 2

GYGLIC AGTIVITY OF UNDERFED FEMALE RATS (EXPERIMENT 2)

\begin{tabular}{c|c|c|c}
\hline \multirow{2}{*}{$\begin{array}{c}\text { Cycle after which } \\
\text { rats became anoestrous }\end{array}$} & \multicolumn{3}{|c}{ No. of underfed rats becoming anoestrous } \\
\cline { 2 - 4 } & No male & $\begin{array}{c}\text { Exposed to } \\
\text { different males } \\
15 \mathrm{hr} / \text { day }\end{array}$ & $\begin{array}{c}\text { Exposed to } \\
\text { same male } \\
\text { continuously }\end{array}$ \\
\hline First cycle & $0 / 10$ & $0 / 10$ & $0 / 10$ \\
Second cycle & $0 / 10$ & $0 / 10$ & $0 / 10$ \\
Third cycle & $1 / 10$ & $0 / 10$ & $0 / 10$ \\
Fourth cycle & $1 / 10$ & $1 / 10$ & $9 / 10$ \\
\hline
\end{tabular}

The frequency of oestrus in the underfed groups associated with males is shown in Text-fig. 4. Continuous exposure to the same male significantly increased the rate at which cyclic activity ceased as shown by the difference in slope of the regression lines $(P<0.001)$.

The uteri of underfed females killed at the fourth cycle after exposure to different males $15 \mathrm{hr} /$ day had a significantly heavier wet uterus $(P<0.001)$, blotted uterus $(P<0.001)$ and uterine fluid weight $(P<0.01)$ compared to underfed females in the absence of males (Table 3 ). It was not possible to obtain values in the continuously associated group since most had become anoestrous by the fourth cycle.

\section{Experiment 3}

Daily frequencies of oestrus for Groups 8, 9 and 10 are shown in Text-fig. 5, together with regression analyses. In the July and January groups (8 and 10), there was no significant correlation between frequency of oestrus and time. In the October group (9), there was a significant negative correlation $(P<0.01)$. 


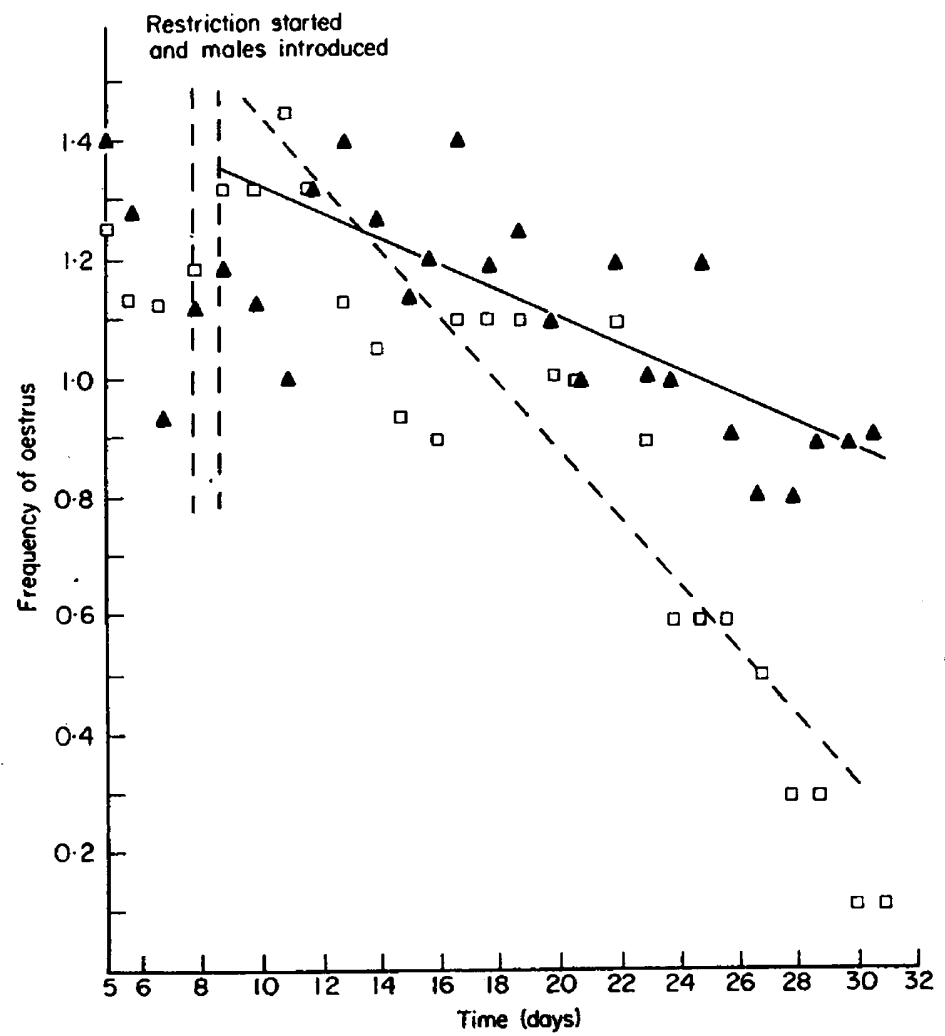

TExT-Fic. 4. Frequency of oestrus in two groups of rats from Exp. 2: (a) fed a restricted diet in the continuous presence of the same male, $\square$; regression line (Day 10 to 32 - - - - ) $y=1.97-0.05 x, r=-0.85$; (b) fed a restricted diet whilst periodically exposed to different males, $\Delta$; regression line (Day 10 to $32 \stackrel{\text { ) }}{\longrightarrow}=1.54-0.02 x, r=$ -0.67 . Explanation as for Text-fig. 2 .

TABLE 3

MEAN PRO-OESTROUS UTERINE WEIGHTS (MG/100 G BODY WT) \pm S.E. OF UNDERFED FEMALE RATS (EXPERIMENT 2)

\begin{tabular}{l|c|c}
\hline & \multicolumn{2}{|c}{ Killed after fourth oestrous cycle } \\
\cline { 2 - 3 } & No male $(7)^{*}$ & $\begin{array}{c}\text { Exposed to different } \\
\text { males } 15 \text { hr/day (7) }\end{array}$ \\
\hline Wet uterine weight & $226.91 \pm 31.3$ & $404.6 \pm 19.2$ \\
Blotted uterine weight & $161.9 \pm 11.3$ & $232.0 \pm 9.0$ \\
Fluid weight & $64.4 \pm 28.3$ & $171.6 \pm 18.9$ \\
\hline
\end{tabular}

* No. of rats in parentheses. 


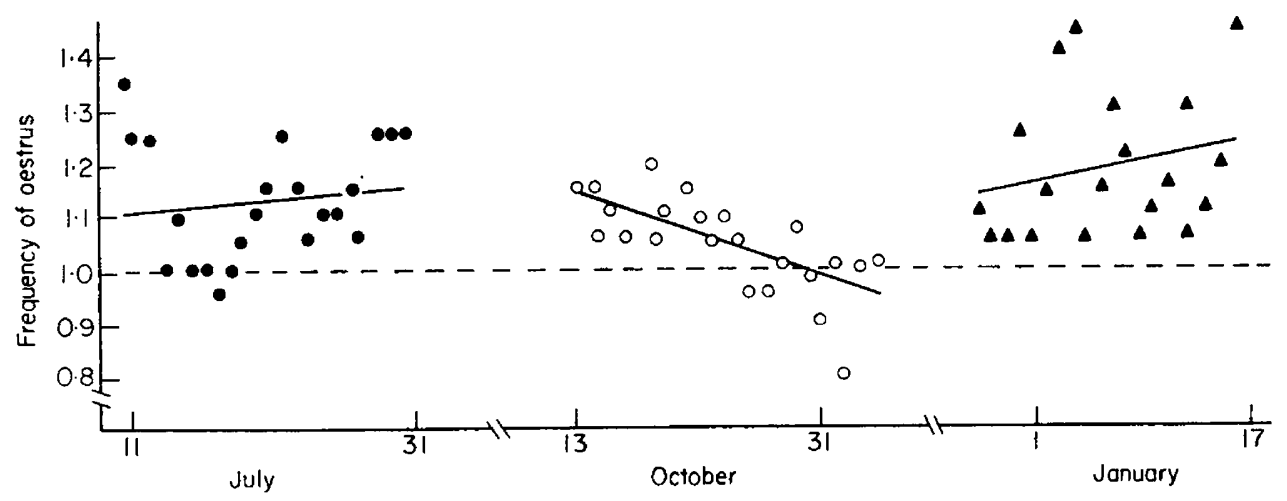

TexT-Fig. 5. Frequency of oestrus in three groups of rats from Exp. 3: (8) during JulyAugust; regression line $(\bullet) y=1.105+0.002 x, r=0.11$; (9) during October-November; regression line (O) $\mathrm{y}=1.150-0.009 \mathrm{x}, \mathrm{r}=0.63$; (10) during December-January; regression line $(\Delta) \mathrm{y}=1 \cdot 128+0.005 \mathrm{x}, \mathrm{r}=0.21$. Explanation as for Text-fig. 2 .

\section{DISCUSSION}

The present findings suggest that the previously observed stimulatory effect of male rat proximity on cycle lengths of the underfed female (Cooper \& Haynes, 1967; McNeilly et al., 1970) is more complex than was originally thought. The continuous presence of one male with one underfed female caused a marked depression of cyclic activity after an initial stimulation, with a greater tendency for cyclic activity to cease compared to underfed control animals or underfed animals in discontinuous association with different males. The fact that this arrest is quite abrupt, most animals reaching this state after the third or fourth cycle, indicates that the time factors involved are remarkably constant. Underfed females, therefore, do not appear to show an individual and varied reaction to continuous male proximity as they do to nutritional stress alone (Cooper \& Haynes, 1967) but, instead, show a more standard response.

The overall responses to undernutrition in the presence of a male in Exps 1 and 2 were the same but differences in magnitude were apparent. In Exp. 1, carried out during November and December, the animals were more sensitive than those in Exp. 2, carried out in February and March; the effects of undernutrition were marked by the first cycle in Exp. 1 but did not become evident until the second cycle in Exp. 2. Also, the majority of underfed animals in continuous association with males in Exp. 1 became anoestrous after the third cycle compared to the fourth cycle in Exp. 2. The difference in sensitivity was not limited to underfed animals. In Exp. 1, the fully fed animals were more sensitive to environmental changes than those in Exp. 2; continuous exposure of female rats, fed on unrestricted intake, to males resulted in a depressed frequency of oestrus but this was not confirmed in Exp. 2. It is suggested that the variability in sensitivity between experiments may be a result of season and evidence for seasonality under different circumstances is provided by the results of Exp. 3 which formed part of an independent study carried out by a different 
person in different rooms. Fully fed animals showed a tendency to increase cycle lengths in October even when isolated from all male contact and were presumably very sensitive to non-specific stimuli; an effect not observed at periods on either side of this time. The animals in all experiments were maintained under constant environmental conditions with regard to lighting pattern and temperature and the most likely environmental cue which could have varied with season was the diet. Whilst the animals were fed a standard compounded ration, the quality of ingredients may alter with the time of year and the changes in external environment may have been transmitted to the animal through the food supply.

The apparently deleterious effect of continuous exposure to a male rat on the reproductive activity of the female is in accord with observations on the reproduction of heteromyid rodents (Eisenberg \& Isaac, 1963). Pairing experiments in this species indicated that the continuous proximity of the male may cause the female to stop cycling and enter a prolonged anoestrus. Successful breeding demands that the sexes dwell separately, coming together for mating with only a brief pairing interval. There are also precedents for this type of effect in a reverse situation since the arousal value a particular female rat has for a male seems to be limiting; the desire of the male to copulate decreasing with time. The male retains copulatory ability, however, if the female is constantly changed. It is suggested that this decline in response to the same female may reflect adaptation to particular stimulus conditions (Fisher, 1958, 1962; Wilson, Kuehn \& Beach, 1963; Beach \& Ransom, 1967). In these reports, however, physical contact between male and female was allowed. In the experiments described here, physical contact was not possible and proximity was the only prerequisite for the response.

The observations reported in this paper do not indicate whether the stimulatory effect of discontinuous association is a result of periodic removal and reintroduction of the stimulus or of regular alteration of the stimulus by the use of different males, or a combination of both. Further experiments are in progress to clarify this situation.

The significantly larger uterus and uterine fluid in the group in discontinuous association with different males compared to controls shows that the effect is not limited to cyclic activity and that endocrine changes are probably involved. Since alterations in uterus weight and increased fluid content are usually associated with changes in the FSH activity, the results are in accord with those of Bronson \& Desjardins (1969), who correlated high levels of hypophysial and plasma FSH in gonadectomized female mice with exposure to male mice.

In summary, whilst the mechanisms remain obscure, it is apparent that association of female rats with different males for discontinuous periods during underfeeding stimulates reproductive activity for a period of at least four cycles and counteracts the effects of underfeeding. Continuous pairing with a male, however, at a critical time when the female is attempting to offset the effects of undernutrition, accelerates the retarding effects of diet restriction on the reproductive process. In both cases, proximity is sufficient to elicit a response and physical contact does not seem to be necessary. 


\section{REFERENCES}

BeACH, F. A. \& Ransom, T. W. (1967) Effects of environmental variation on ejaculatory frequency in male rats. F. comp. physiol. Psychol. 64, 384.

Bronson, F. H. \& Desjardins, G. (1969) Release of gonadotrophin in ovariectomized mice after exposure to males. F. Endocr. 44, 293.

COOPER, K. J. \& HAYNES, N. B. (1967) Modification of the oestrous cycle of the underfed rat associated with the presence of the male. F. Reprod. Fert. 14, 317.

Cooper, K. J., Haynes, N. B. \& Lamming, G. E. (1970) The effects of unrestricted feeding during oestrus on reproduction in the underfed female rat. $\mathcal{F}$. Reprod. Fert. 22, 293.

EisenberG, J. F. \& IsAAG, D. E. (1963) The reproduction of heteromyid rodents in captivity. $\mathcal{J}$. Mammal. 44, 61 .

Fisher, A. E. (1958) Effects of stimulus variation on sexual satiation in the male rat. Am. Psychol.13, 382.

Fisher, A. E. (1962) Effects of stimulus variation on sexual satiation in the male rat. F. comp. physiol. Psychol. 55, 614 .

Hughes, R. L. (1964) Effects of changing cages, introduction of the male and other procedures on the oestrous cycle of the rat. C.S.I.R.O. Wildl. Res. 9, 115.

MaNeirly, A. S., Cooper, K. J. \& Grighton, D. B. (1970) Modification of the oestrous cycle of the underfed rat induced by the proximity of a male. $\mathcal{7}$. Reprod. Fert. 22, 359.

RADFORD, H. M. \& WATSON, R. H. (1957) Influence of rams on ovarian activity and oestrus in Merino ewes in the spring and early summer. Aust. F. agric. Res. 8, 460.

Schinckel, P. G. (1954) The effects of the presence of the ram on the ovarian activity of the ewe. Aust. F. agric. Res. 5, 465.

Shelton, M. (1960) Influence of the presence of a male goat on the initiation of estrous cycling and ovulation of Angora does. J. Anim. Sci. 19, 368

Signoret, J. P. \& DU Mesnil du Buisson, F. (1961) Etude du comportement de la truie en oestrus. Proc. IVth Int. Congr. Anim. Reprod., The Hague, p. 171.

Whitren, W. K. (1958) Modifications of the oestrous cycle of the mouse by external stimuli associated with the male. Changes in the oestrous cycle detected by vaginal smears. $\tilde{\mathcal{F}}$. Endocr. 17, 307.

Wirson, J., KUEHN, R. \& BEAGH, F. (1963) Modification in the sexual behaviour of male rats produced by changing the stimulus female. F. comp. physiol. Psychol. 56, 636. 